\title{
Effect of Story-Telling on Reducing the Intensity of Nausea and Vomiting among Children Undergoing Chemotherapy
}

Semha Abd El Nasser El Sayed ${ }^{1}$, Hekmat Ibrahim ${ }^{2}$, Nahed Thabet Mohamed ${ }^{3}$ \& Manal Mohamed Ahmed ${ }^{4}$.

1. Clinical Demonstrator in Pediatric Nursing, Faculty of Nursing, Sohag University, Egypt.

2. Professor of Pediatric \& Premature Nursing, Faculty of Nursing, Assiut University Lecturer of Pediatric and premature Nursing, Faculty of Nursing, Assiut University, Egypt .

3. Assistant Professor of Pediatric Nursing, Faculty of Nursing, Assiut University, Egypt.

4. Lecturer of Pediatric Nursing, Faculty of Nursing, Sohag University, Egypt.

\begin{abstract}
The study aimed to assess the effect of storytelling on reducing intensity of nausea and vomiting in children undergoing chemotherapy. Design: Quasi-experimental research design was used in the study. Subjects: 200 children were equally and randomly assigned into two groups, the first was the control group, the second was story telling group, their age ranged from 3-6. Setting: the study conduct years at Oncology institute at Sohag City and Sohag university hospital. Tools: an Interview Structured Questionnaire was developed by the researcher and Rhodes Index of Nausea and Vomiting Likert scale was utilized for collecting the data. Results: statistically significant difference was detected among the studied children as regards the occurrence frequency of nausea per 24 hours with mean $\pm \mathrm{SD}(1.63 \pm 1.22$ after the intervention compared to $3.63 \pm 2.88$ before the intervention. A statistically significant difference was detected between the two groups as regards of vomiting before and after the intervention. Conclusion: children who exposed to story - telling experienced lower intensity of nausea and vomiting compared to children in the control group who received routine hospital care. Recommendations: They should include telling story and parents' education about non pharmacological management for nausea and vomiting.
\end{abstract}

\section{Keywords: Story-Telling, Intensity of Nausea and Vomiting, Children \& Chemotherapy.}

\section{Introduction}

Cancer is a major health concern for people in the general population it is estimated that one in four people will develop cancer and that more than half of those diagnosed will die from the disease and some tumors are more common. There are different risk factors for developing cancer and different needs for both medical and psychosocial care provision (Zhang et al., 2015).

Childhood cancer is still a big problem because; children's cancer can't be treated exactly like adult cancers where most of federal research funding goes. Current treatments are toxic, affect a child's development and can be decades old. To treat childhood cancer in the best way possible, we must create specialized treatment just for kids. The causes of childhood cancer are largely unknown (Kashaninia et al., 2016).

Cancer is treated with chemotherapy; chemotherapy is given in cycles, with each period of treatment followed by a rest period to give the body time to recover from the effects of the drugs. Cycles are most often 2 or 3 weeks long. Chemotherapy begins on the first day of each cycle, but the schedule varies depending on the drugs used (American Cancer Society, 2015). Moreover, Chemotherapeutic agents can be divided into several classes based on mechanism of action, chemical structure, biologic source, or effect on the cell cycle the nurse must be able to help the child to assume a comfortable position, provide emotional support, and explain the actions to be taken. The nurse should also teach the patient relaxation techniques and instruct him/ her to exercise hand with a rubber ball daily between treatments. This aids in vein development to dilate the veins (Heinemann \& Boyce, 2012).

Chemotherapy induced nausea and vomiting is one of the most distressing acute side effects of cancer treatment; it occurs in up to $80 \%$ of pediatrics (National Cancer Institute, 2017). Treatments with chemotherapy may go on for many months. Therefore, an important role of the nurse during IV chemotherapy is to maintain venous integrity (Sheikhi et al., 2015).

Some researchers advocated that listening to short stories and playing with toys are the most effective techniques used with the preschool child during an acute nausea experience in many settings (Academy for Guided Imagery, 2010).

Story telling is a distraction and the distraction is a key strategy for children. Distraction is a low cost intervention that has no risk for the patient and has a measurable benefit, as it reduces the amount of observed distress behavior for most children during medical procedures and the side effects of chemotherapy such as nausea and vomiting (Shapiro, 2011). 
Children enjoy listening to stories. Stories induce motivation and fun. Children can become personally involved in a story (Scott, 2010).

Role of the nurse during chemotherapy include that nurse should not prepare drugs in eating area should be prepare in custom room and should be performed over plastic absorbing pads. Nurses should not allow anyone to interrupt her/him during the preparation of the drug (King, 2011). The nurse must inspect for clarity of infusion prior to administration, and must protect IV lines and needles placement with arm board (Sheikhi et al., 2015).

\section{Significance of the study}

Nausea and vomiting are the most common and unpleasant side effects of chemotherapy, they may interfere with patient compliance to treatment completion and may be associated with considerable health care resource utilization (Burke etal. 2016). In association with traditional use of antiemetics for control of nausea and vomiting, it is necessary to find other methods for better control of side effects (Mazlumal et al., 2013). There is a lack of studies which discuss the importance of story-telling as types of distraction on children with cancer, so that the current study will assess the effect of storytelling on reducing intensity of nausea and vomiting in children undergoing chemotherapy.

\section{Aim of the study}

To assess the effect of story-telling on reducing intensity

of nausea and vomiting in children undergoing chemotherapy.

\section{Research hypothesis}

Children undergoing chemotherapy that listens to story-telling

have a lower intensity and frequency of nausea and vomiting compared with children in the control group.

\section{Materials \& Method \\ Research design}

Aquasi-experimental research design was used in this study.

\section{Setting}

The study was conducted in the pediatric department at Oncology institute at Sohag city and Sohag university hospital, the setting was select because it's near my home and work

\section{Subjects}

Randomization technique was used to collect data. The study subjects included all children received chemotherapy, in the previous setting within six months, who equally assigned into two groups, the first which was the control group 100 (children), the second was story telling group (study group), their ages ranged from 3-6 years. We used the coin in selecting the sample where the face of writing is selected for control group and the face of king is selected for study group.

The criteria for the selection of the study subjects were

1. Children aged from $(3-6)$ years.

2. Conscious children.

Tools of the study

Tool I: An Interview Structured Questionnaire, this tool was developed by the researcher after reviewing the related literature; it included two parts

Part I : Personal characteristics of the child as, age, sex and birth order.

Part II: Clinical data it includes child's diagnosis, medical history about cancer which include (family history of cancer, duration of the disease, chemotherapy treatment methods) the side effects of chemotherapy such as, nausea, vomiting, joint pain, oral ulcer, headache, anorexia......etc.

Tool (2): Rhodes Index of Nausea and Vomiting Likert scale

This tool was adopted by Rhodes \& McDanial, (1999), it used to assess nausea and vomiting for children receiving chemotherapy assess the number of vomiting episodes per day, the quality and quantity of vomiting, degree and length of nausea. The constructed tool has 24 items, include 3 parts, the first part assess anticipatory nausea and vomiting and contain 8 items, the second part assess acute nausea and vomiting which contain 8 items and third part assess delayed nausea and vomiting which contain 8 items captures all the characteristics of nausea and vomiting. Internal consistency was tested by using Cronbach's alpha and it was 0.97 .

\section{Scoring system}

1. For the questions that have "yes" or "no" answer, "yes" was assigned a value of " 1 ", and " no" was assigned a value of " 0 ."

2. For questions asking about the duration of nausea, if the duration is less than one hour, the score is "1", if the duration is more than one hour, the score is " $2 . "$

3. For the questions asking about the severity of nausea and vomiting, mild was assigned a value of "1", moderate was assigned a value of " 2 ", severe was assigned a value of " 3 ", and intolerable was assigned a value of " $4 . "$

4. For the questions asking about the frequency of nausea and vomiting, "once" was assigned a value of "1", "twice" was assigned a value of "2" and so on.

5. For the questions asking about the estimation of the amount of vomiting, "small amount" was assigned a value of "1", "moderate amount" was 
assigned a value of " 2 ", and "large amount" was assigned a value (Rhodes \& McDaniel, 1999).

6. Scoring system: items o scale are divided into 4 categories mild, moderate, sever and intolerable in study group, mild was $97(97,0 \%)$, moderate was $2(2,0 \%)$, sever was $1(1,0)$ intolerable 0 $(0,0)$, where in control group, it's also divided into 4 categories mild, moderate, sever, intolerable, where mild was $50(50,5 \%)$, moderate was $26(26,3 \%)$,sever was $17(1,2)$ and intolerable $6(6,1)$.

\section{Tool validity}

Content validity of the tools was determined through the data collection tools were submitted to a panel of five experts in Pediatric Nursing and Pediatric Oncology with more than ten years of experience in the field. Modifications of the tools was done according to the panel judgment on clarity of sentences, appropriateness of the content, sequence of items, and accuracy of scoring and recording of the items.

\section{Tool Reliability}

Tool Reliability The tools reliability was estimated through using the Pearson correlation coefficient test to compare between variables. The findings from the validity and reliability suggested that, the tools of the study could be used as valid and reliable data collection tools for the current study. Tools reliability was tested using internal consistency methods (Alpha Cronbach's test assessment tool, its result was $(0.88,0$, and 91$)$ which indicates good reliability of the tool. Internal consistency of Rhodes scale was tested by using Cronbach's alpha and it was 0.97 . The content reliability index was 0.88 , Scoring system if no nausea and vomiting $=0$ if yes $=1$, for answer mild $=1$, moderate $=2$, sever $=3$, intolerable $=4$.

\section{Method of data collection}

The study was carried out after gaining the necessary approval

and an official permission was obtained from the chairman of Oncology Institute at Sohag City and Sohag University Hospital.

A written consent was obtained from the child's parents to collect the data after explaining the purpose and the nature of the study; data were collected from March to August 2018.

\section{Ethical consideration}

1. Research proposal was approved from Ethical Committee

in the Faculty of nursing, Assuit University.

2. There was no risk for study subjects during application of the research.

3. The study followed common ethical principles in clinical research.
4. Study subjects have the right to refuse to participate or withdraw from the study without any rational at any time.

5. Study subjects privacy was considered during collection of data.

\section{Pilot study}

It was carried out on $10 \%$ of children, to test the clarity

and applicability of the tools and estimate the time needed for data collection. Based on the result of the pilot study no modification was done in the tools, the children in the pilot were included from total sample.

\section{Field work}

1. The researcher first introduced herself to the mothers and then explained the purpose of the study at the beginning of the interview, so the mothers were reassured that all gathered information was confidential.

2. The interview was conducted in five day through the week.

3. The average time for filling the sheet was around $30-45$ minutes depending on the response of the mothers.

4. Nausea and vomiting incidences were documented during and after chemotherapy.

5. The researcher was told story during chemotherapy procedure, and continued throughout the procedure during which nausea and vomiting was assessed by using the selected tool by the researcher and this was divided into two phases:

The first phase: Include telling story that took about thirty minutes by using a fun and educational story type, which consisting of pages with colorful and attractive graphics and one line or one sentence per page. These stories are revolved around things the child knows, such as his or her family and compassion for nature. These stories that may attract the child and raise his attention had be returned and share with the child meaning while telling the story and make the child repeat it.

The second phase: Include discussion about the story with the child that took about forty-five minutes after that assess the characteristics of nausea and vomiting through using the Rhodes index for nausea and vomiting

\section{Statistical analysis}

Date entry and data analysis were done using SPSS version 19 (Statistical Package for Social Science). Data were presented as number, percentage, mean, median and standard deviation. Chi-square test and Fisher exact test were used to compare qualitative variables. Mann-Whitney test was used to compare 
quantitative variables between two groups. P-value

considered statistically significant when $\mathrm{P}<0.05$.

Results

Table (1): Personal data of children in study and control groups

\begin{tabular}{|c|c|c|c|c|c|}
\hline & \multicolumn{2}{|c|}{$\operatorname{Study} \operatorname{group}(\mathbf{n}=100)$} & \multicolumn{2}{|c|}{ Control group $(n=100)$} & \multirow{2}{*}{ P-value } \\
\hline & No & $\%$ & No & $\%$ & \\
\hline \multicolumn{6}{|l|}{ Age: (years) } \\
\hline $3-<4$ & 5 & $(5.0 \%)$ & 4 & $(4.0 \%)$ & \multirow{3}{*}{0.514} \\
\hline $4-<5$ & 57 & $(57.0 \%)$ & 50 & $(50.0 \%)$ & \\
\hline $5-6$ & 38 & $(38.0 \%)$ & 46 & $(46.0 \%)$ & \\
\hline Mean \pm SD & \multicolumn{2}{|c|}{$4.57 \pm 0.75$} & \multicolumn{2}{|c|}{$4.70 \pm 0.82$} & \multirow{2}{*}{0.327} \\
\hline Range & \multicolumn{2}{|c|}{$3.0-6.0$} & \multicolumn{2}{|c|}{$3.2-6.0$} & \\
\hline \multicolumn{5}{|l|}{ Sex: } & \multirow{3}{*}{0.671} \\
\hline Male & 54 & $(54.0 \%)$ & 51 & $(51.0 \%)$ & \\
\hline Female & 46 & $(46.0 \%)$ & 49 & $(49.0 \%)$ & \\
\hline \multicolumn{5}{|l|}{ Birth order: } & \multirow{4}{*}{0.088} \\
\hline First & 35 & $(35.0 \%)$ & 21 & $(21.0 \%)$ & \\
\hline $2 \mathrm{nd}-3^{\text {rd }}$ & 39 & $(39.0 \%)$ & 47 & $(47.0 \%)$ & \\
\hline Fourth or more & 26 & $(26.0 \%)$ & 32 & $(32.0 \%)$ & \\
\hline
\end{tabular}

Table (2): Medical diagnosis of children in studied and control groups.

\begin{tabular}{|l|c|c|c|c|c|}
\hline \multirow{2}{*}{\multicolumn{1}{c|}{ Diagnosis }} & \multicolumn{2}{c|}{ Study $(\mathbf{n = 1 0 0})$} & \multicolumn{2}{c|}{ Control $(\mathbf{n}=\mathbf{1 0 0})$} & \multirow{2}{*}{ P-value } \\
\cline { 2 - 5 } & No & $\mathbf{\%}$ & No & \% & \\
\hline Brain tumor & 6 & $(6.0 \%)$ & 15 & $(15.0 \%)$ & $0.038^{*}$ \\
\hline Kidney tumor & 8 & $(8.0 \%)$ & 7 & $(7.0 \%)$ & 0.788 \\
\hline Leukemia & 47 & $(47.0 \%)$ & 40 & $(40.0 \%)$ & 0.318 \\
\hline Pelvic tumor & 16 & $(16.0 \%)$ & 18 & $(18.0 \%)$ & 0.707 \\
\hline Thyroid tumor & 22 & $(22.0 \%)$ & 15 & $(15.0 \%)$ & 0.202 \\
\hline Pulmonary Tumor & 1 & $(1.0 \%)$ & 5 & $(5.0 \%)$ & 0.212 \\
\hline
\end{tabular}

Table (3): Medical history about cancer among children in studied and control groups.

\begin{tabular}{|c|c|c|c|c|c|}
\hline \multirow{2}{*}{ Items } & \multicolumn{2}{|c|}{ Study $(n=100)$} & \multicolumn{2}{|c|}{ Control $(n=100)$} & \multirow{2}{*}{ P-value } \\
\hline & No & $\%$ & No & $\%$ & \\
\hline \multicolumn{5}{|c|}{ Family history of cancer: } & \multirow{3}{*}{0.195} \\
\hline Yes & 36 & $(36.0 \%)$ & 45 & $(45.0 \%)$ & \\
\hline No & 64 & $(64.0 \%)$ & 55 & $(55.0 \%)$ & \\
\hline \multicolumn{5}{|l|}{ Duration of disease: } & \multirow{4}{*}{0.541} \\
\hline One year & 70 & $(70.0 \%)$ & 73 & $(73.0 \%)$ & \\
\hline Two years & 21 & $(21.0 \%)$ & 22 & $(22.0 \%)$ & \\
\hline Three years or more & 9 & $(9.0 \%)$ & 5 & $(5.0 \%)$ & \\
\hline \multicolumn{5}{|c|}{ Chemotherapy treatment methods: } & \multirow{3}{*}{$0.000 *$} \\
\hline Infusion & 68 & $(68.0 \%)$ & 22 & $(22.0 \%)$ & \\
\hline Infusion + IM & 32 & $(32.0 \%)$ & 78 & $(78.0 \%)$ & \\
\hline \multicolumn{6}{|c|}{ Side effects of chemotherapy: $*$} \\
\hline Nausea & 29 & $(29.0 \%)$ & 59 & $(59.0 \%)$ & $0.000 *$ \\
\hline Vomiting & 32 & $(32.0 \%)$ & 100 & $(100.0 \%)$ & $0.000 *$ \\
\hline Oral ulcer & 57 & $(57.0 \%)$ & 51 & $(51.0 \%)$ & 0.395 \\
\hline Joint pain & 37 & $(37.0 \%)$ & 54 & $(54.0 \%)$ & $0.016^{*}$ \\
\hline Anorexia & 39 & $(39.0 \%)$ & 60 & $(60.0 \%)$ & $0.003 *$ \\
\hline Headache & 38 & $(38.0 \%)$ & 30 & $(30.0 \%)$ & 0.232 \\
\hline Drowsiness & 26 & $(26.0 \%)$ & 12 & $(12.0 \%)$ & $0.012 *$ \\
\hline
\end{tabular}

Vol , (7) No , (17) June, 2019 


\begin{tabular}{|l|c|c|c|c|c|}
\hline \multirow{2}{*}{\multicolumn{1}{|c|}{ Items }} & \multicolumn{2}{c|}{ Study (n= 100) } & \multicolumn{2}{c|}{ Control (n= 100) } & \multirow{2}{*}{ P-value } \\
\cline { 2 - 6 } & No & \% & No & \% & \\
\hline General weakness & 41 & $(41.0 \%)$ & 21 & $(21.0 \%)$ & $0.002^{*}$ \\
\hline Constipation & 14 & $(14.0 \%)$ & 4 & $(4.0 \%)$ & $0.013^{*}$ \\
\hline Stomachache & 14 & $(14.0 \%)$ & 3 & $(3.0 \%)$ & $0.005^{*}$ \\
\hline Alopecia & 0 & $0(0.0 \%)$ & 9 & $(9.0 \%)$ & $0.003^{*}$ \\
\hline
\end{tabular}

*more than one was available

Table (4): Percentage distribution of children according to items of Rhodes index of nausea and vomiting scale during anticipatory nausea and vomiting.

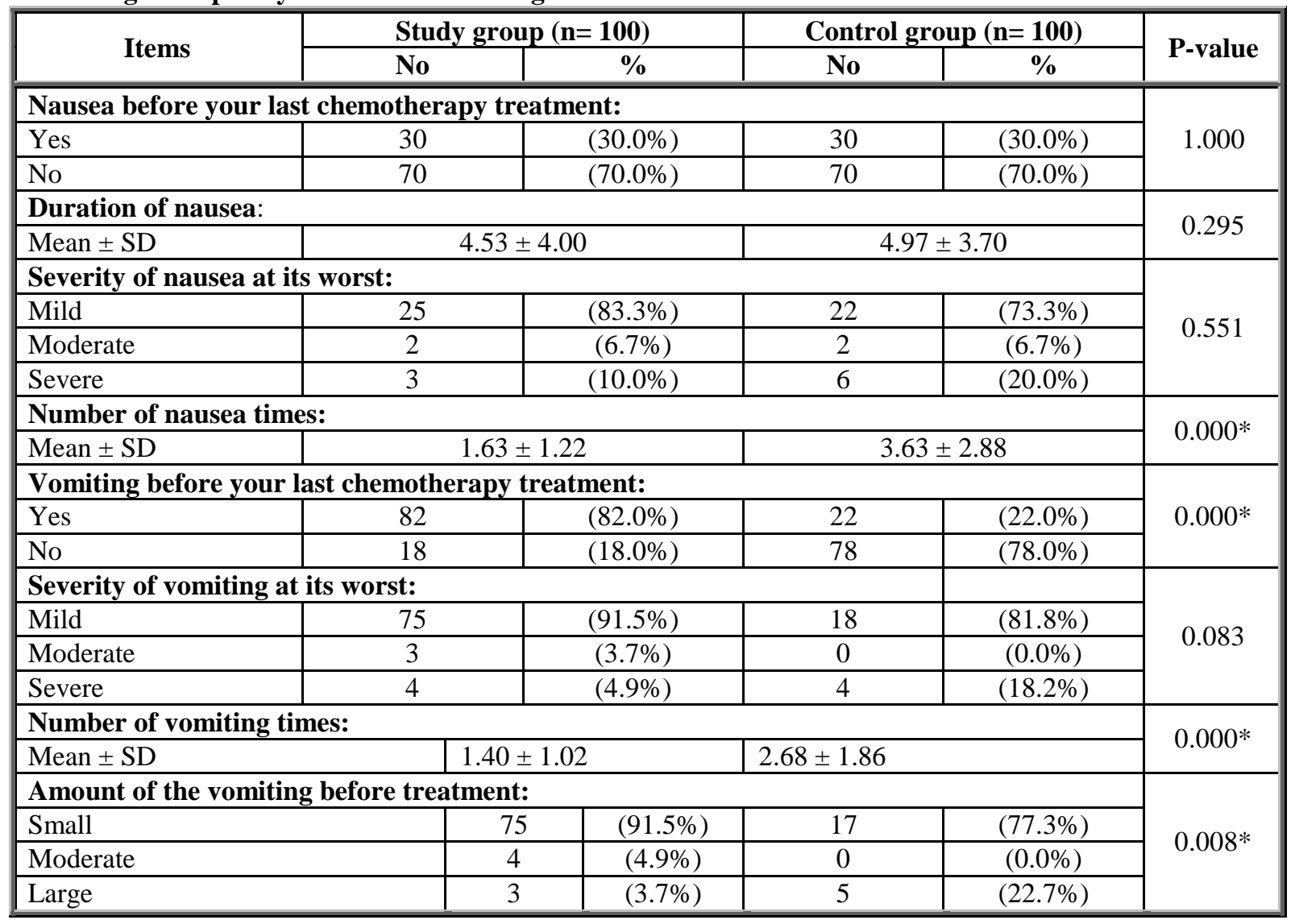

Table (5): Percentage distribution of children according to items of Rhodes index of nausea and vomiting scale during acute nausea and vomiting.

\begin{tabular}{|c|c|c|c|c|c|}
\hline \multirow{2}{*}{ Items } & \multicolumn{2}{|c|}{ Study $(n=100)$} & \multicolumn{2}{|c|}{ Control $(n=100)$} & \multirow{2}{*}{ P-value } \\
\hline & No & $\%$ & No & $\%$ & \\
\hline \multicolumn{5}{|c|}{ Nausea during or within 24 hours of your last chemotherapy treatment: } & \multirow{3}{*}{$0.000 *$} \\
\hline Yes & 0 & $(0.0 \%)$ & 22 & $(22.0 \%)$ & \\
\hline No & 100 & $(100.0 \%)$ & 78 & $(78.0 \%)$ & \\
\hline \multicolumn{5}{|c|}{ Vomiting during or within 24 hours of your last treatment: } & \multirow{3}{*}{$0.000 *$} \\
\hline Yes & 2 & $(2.0 \%)$ & 100 & $(100.0 \%)$ & \\
\hline No & 98 & $(98.0 \%)$ & 0 & $(0.0 \%)$ & \\
\hline \multicolumn{5}{|c|}{ Severity of vomiting at its worst: } & \multirow{5}{*}{0.558} \\
\hline Mild & 1 & $(50.0 \%)$ & 80 & $(80.0 \%)$ & \\
\hline Moderate & 0 & $(0.0 \%)$ & 5 & $(5.0 \%)$ & \\
\hline Severe & 1 & $(50.0 \%)$ & 14 & $(14.0 \%)$ & \\
\hline Intolerable & 0 & $(0.0 \%)$ & 1 & $(1.0 \%)$ & \\
\hline
\end{tabular}




\begin{tabular}{|c|c|c|c|c|c|}
\hline \multirow{2}{*}{ Items } & \multicolumn{2}{|c|}{ Study $(n=100)$} & \multicolumn{2}{|c|}{ Control $(n=100)$} & \multirow{2}{*}{ P-value } \\
\hline & No & $\%$ & No & $\%$ & \\
\hline \multicolumn{5}{|c|}{ Number of vomiting during or within 24 hours of treatment: } & \multirow{3}{*}{0.844} \\
\hline Mean \pm SD & \multicolumn{2}{|c|}{$5.50 \pm 6.36$} & \multicolumn{2}{|c|}{$3.35 \pm 2.35$} & \\
\hline Range & \multicolumn{2}{|c|}{$1.0-10.0$} & \multicolumn{2}{|c|}{$1.0-10.0$} & \\
\hline \multicolumn{5}{|c|}{ Amount of the vomiting: } & \multirow{4}{*}{0.505} \\
\hline Small & 1 & $(50.0 \%)$ & 77 & $(77.0 \%)$ & \\
\hline Moderate & 0 & $(0.0 \%)$ & 5 & $(5.0 \%)$ & \\
\hline Large & 1 & $(50.0 \%)$ & 18 & $(18.0 \%)$ & \\
\hline
\end{tabular}

Table (6): Percentage distribution of children in study and control group according to items of Rhodes index of nausea and vomiting scale during delayed nausea and vomiting

\begin{tabular}{|c|c|c|c|c|c|}
\hline \multirow{2}{*}{ Items } & \multicolumn{2}{|c|}{ Study $(n=100)$} & \multicolumn{2}{|c|}{ Control $(n=100)$} & \multirow{2}{*}{ P-value } \\
\hline & No & $\%$ & No & $\%$ & \\
\hline \multicolumn{5}{|c|}{ Nausea during 24 hour or more of your last chemotherapy treatment: } & \multirow{3}{*}{$0.000^{*}$} \\
\hline Yes & 0 & $(0.0 \%)$ & 18 & $(18.0 \%)$ & \\
\hline No & 100 & $(100.0 \%)$ & 82 & $(82.0 \%)$ & \\
\hline \multicolumn{5}{|c|}{ Duration of nausea : } & \multirow{3}{*}{0} \\
\hline Mean \pm SD & & & & 4.56 & \\
\hline Range & & & & 5.0 & \\
\hline \multicolumn{5}{|c|}{ Severity of nausea: } & \multirow{4}{*}{0} \\
\hline Mild & 0 & 0.0 & 10 & $(55.6 \%)$ & \\
\hline Moderate & 0 & 0.0 & 2 & $(11.1 \%)$ & \\
\hline Severe & 0 & 0.0 & 6 & $(33.3 \%)$ & \\
\hline \multicolumn{5}{|c|}{ Number of nausea times: } & \multirow{3}{*}{0} \\
\hline Mean \pm SD & & & & 2.30 & \\
\hline Range & & & & & \\
\hline \multicolumn{5}{|c|}{ Vomiting 24 hour or more of your last treatment: } & \multirow{3}{*}{$0.000 *$} \\
\hline Yes & 2 & $(2.0 \%)$ & 100 & $(100.0 \%)$ & \\
\hline No & 98 & $(98.0 \%)$ & 0 & $(0.0 \%)$ & \\
\hline \multicolumn{5}{|c|}{ Severity of vomiting: } & \multirow{4}{*}{$0.009 *$} \\
\hline Mild & 0 & $(0.0 \%)$ & 78 & $(78.0 \%)$ & \\
\hline Moderate & 0 & $(0.0 \%)$ & 6 & $(6.0 \%)$ & \\
\hline Severe & 2 & $(100.0 \%)$ & 16 & $(16.0 \%)$ & \\
\hline \multicolumn{5}{|c|}{ Number of vomiting times: } & \multirow{3}{*}{0.064} \\
\hline Mean \pm SD & \multirow{2}{*}{\multicolumn{2}{|c|}{$\frac{7.50 \pm 4.95}{4.0-11.0}$}} & \multicolumn{2}{|c|}{$3.04 \pm 2.60$} & \\
\hline Range & & & \multicolumn{2}{|c|}{$1.0-12.0$} & \\
\hline \multicolumn{5}{|c|}{ Amount of the vomiting: } & \multirow{4}{*}{$0.009 *$} \\
\hline Small & 0 & $(0.0 \%)$ & 78 & $(78.0 \%)$ & \\
\hline Moderate & 0 & $(0.0 \%)$ & 6 & $(6.0 \%)$ & \\
\hline Large & 2 & $(100.0 \%)$ & 16 & $(16.0 \%)$ & \\
\hline
\end{tabular}

Table (1): Shows personal data of both studied and control groups .Regarding to the age, more than half (57\%) of children in the studied group and half of children in the control group were aged $4<5$ years with mean \pm SD $(4.57 \pm 0.75,4.70 \pm$ 0.82 respectively). Males were most prominent in both studied and control groups 54\% and $51 \%$ respectively).

Table (2): Demonstrates that medical diagnosis of children in both studied and control groups. The results represented that no statistical significant difference were found between both groups different diagnosis as kidney tumor, leukemia, pelvic tumor, thyroid tumor and pulmonary tumor, while a statistically significant difference was found as regards Brain tumor $(0.038 *)$.

Table (3): Shows medical history of cancer among children

in study and control groups. The present study indicated that about two thirds (64\%) of the study 
group compared to more than half $55 \%$ of the control groups had no family history of cancer. Also less than three quarters of the both groups (70 $\%$ and $73 \%$ respectively) had cancer since one year. The results represented that more than two thirds of children

in the study group ( $68 \%$ ) were treated with infusion methods while more three quarters in the control group were treated with infusion \& intra muscular methods, with statistically significant difference at $(p=0.000)$. As regards to side effect of chemotherapy the results in the same table also mentioned that nausea and vomiting were ranked as number one side effects $\quad(59 \%$ and $100 \%$ respectively)related to administration of chemotherapy among the majority of children in control group.

Table (4): Illustrates that percentage distribution of children according to items of Rhodes index of nausea and vomiting scale during anticipatory nausea $\&$ vomiting the results the table represents that $70 \%$ of the study and control groups had no nausea before their last chemotherapy treatment . As regards the duration of nausea, the Mean \pm SD were $4.53 \pm 4.00$ for the study group compared to $4.97 \pm$ 3.70 for the control group. In addition the present study indicated that $(3.3 \%$ compared to $73.3 \%$ respectively of the both groups had mild type of nausea.

A statistically significant differences were detected between the study\& control groups as regards number of nausea per 24 hours with mean \pm SD $(1.63 \pm 1.22$ compared to $3.63 \pm 2.88$ respectively. Moreover the results illustrated that a statistically significant differences were detected between the study and control groups as regards vomiting before treatment $(\mathrm{p}=0.000,0.000$ and 0.008).

Table (5): Demonstrates percentage distribution of children according to items of Rhodes index of nausea \&vomiting scale during acute nausea \& vomiting the table found that all children $(100 \%)$ in the study group had no nausea compared to $(78 \%)$ in the control with statistically significant differences $(\mathrm{p}=0.000)$ Nearly all children in the study group $(98 \%)$ compared to $(0.0 \%)$ in the control group had no vomiting during or within 24hours of their last treatment and also a statistically significant differences was detected between the two groups according to vomiting during or within 24 hours of their last treatment $(\mathrm{p}=0.00 \%)$. No statistically significant differences were detected between the two groups as regards severity, number and amount of vomiting.

Table (6): Shows percentage distribution of children according to items of Rhodes index of nausea and vomiting scale during delayed nausea \&vomiting the results indicated that $(100 \%$ compared to $82 \%$ respectively ) in the study and control groups had no vomiting during 24 hours or more of chemotherapy treatment. Also the majority of children in the study group $(98 \%)$ compared to $(0.0 \%)$ of children in the control group had no vomiting. A statistically significant difference was detected between the study and control groups as regards the present of vomiting $\mathrm{p}=(0.000)$, while no statistically significant differences were detected as regards the other items.

\section{Discussion}

Chemotherapy-induced nausea and vomiting are perceived among the most distressing and feared side effect of chemotherapy by patient with cancer. It is estimated that between $60-80 \%$ of cancer patient receiving chemotherapy experienced nausea and vomiting (Kashaninia, 2016).

Poorly control adverse consequences of chemotherapy include nausea and vomiting may lead to increased costs of hospitalizations as result of frequent hospitalization, greater utilization of resources and loss of productivity for both children and care givers. Non pharmacological approaches which include behavioral interventions may provide the greatest promise in reliving symptoms greater evidence supports the use of complementary and alternative methods such as story telling (Ries, 2011).

The present study revealed that males were most prominent in the two groups. These results were in accordance with the results conducted by Worldwide organization (2016) which reported that the incidence of cancer in boys were higher than in girls.

Concerning medical diagnosis of children, the results of the current study revealed that the majority of children had leukemia. These results were similar to study conducted by Abdel Hadi, (2010) who studied comprehensive care in pediatric cancer patient and mentioned that acute lymphatic leukemia was the most common type of cancer in children. Also the result is in same line with Elatter et al., (2008) who investigated cancer statistics, and reported that the most common type of cancer was leukemia; next most common was lymphoma, followed by brain tumors.

Regarding medical history of cancer among children in the two groups, the present study indicated that about two thirds of the study group and more than half of the control group had no family history of cancer. This is explained by the early life exposure to infectious agents, fetal or childhood exposure to environmental toxin such as pesticides, solvents, or other household chemicals, or radiation. 
In relation to the duration of disease, the current study revealed that, less than three quarters of the both groups had cancer since one year. These finding was.

in congruence with the study carried out by Hassan, (2015) who studied "Effect of Guided Imagery Relaxation Session and Story-Telling on the Intensity of Nausea and Vomiting Among Children Undergoing Chemotherapy" and found that approximately one half of children had cancer for less than 6 months. These results were consistent also, with Abd El Razik (2010) who studied "Effect of Educational Program on Quality of life for Patients with cancer undergoing chemotherapy "and found that more than two thirds of children developed cancer for less than one year. This could be due to delayed discovery of cancer to the young age of children.

The current results represented that more than two thirds of children in the studied group were treated with infusion methods. These results were in accordance with the results conducted by Hassan, (2015) who showed that chemotherapy was either administered intravenously or Intrathecally. Also, these results were consistent with Abd El Hadi, (2010) who reported that the majority of children received chemotherapy could be given through different routes depending on the type of cancer and the chemotherapy drugs used. If two or more types of chemotherapy were used together, two different routes of administration could be used. Also, routes of administration are selected according to the rates of absorption of drugs. Nausea and vomiting were ranked as number one side effects related to administration of chemotherapy among the majority of children in control group. This could be related to the toxicity of chemotherapy drug and their harmful effects on normal cells as well as cancer cells.

Hassan, (2015) who found that more than half of children in the three study groups developed nausea\& vomiting before conducting guided imagery relaxation or story telling, these results were consistent with Abdel Hadi, ((2010) who reported that the most common side effects of chemotherapy were nausea, vomiting and fatigue, The current study reflected that low percentage of studied group had nausea and vomiting before their last chemotherapy treatment. In relation to the effect of telling story on nausea and vomiting, the present result revealed that most story telling children didn't develop nausea and vomiting during 24 hours of chemotherapy treatment, children in the control group continued to have nausea and vomiting with different grades.

These results also, agree with Roy (2001) \& Mohammed (2006) who indicated that story telling and video game reduced nausea and vomiting. This could be due to distraction induced by storytelling. This findings also, was similar to Marler (2008) who found children who experienced the telling story group had reduced of the occurrence of nausea and vomiting., This result was in the same line with the result conducted by Hassan, (2015) who mentioned in his study that, approximately all children who receive telling story didn't develop nausea and vomiting, also children in the telling story group had less frequent, children in study group had low intense of nausea and vomiting and smaller amount than children in control group.

This could be due to children's attention was occupied by distraction task activation was reduced in the areas of the brain that were responsible for the occurrence of nausea and vomiting such as thalamus, insula, and the anterior cingulated cortex (Martin, 2010).

\section{Conclusion}

The present study concluded that, children who were exposed to storytelling had experienced low intensity of nausea and vomiting compared to children in the control group who received routine hospital care.

\section{Recommendations}

In the light of the findings obtained from the current study the following recommendations were suggested:

1. In service education programs are needed to upgrade nurse's management about nausea and vomiting among children undergoing chemotherapy.

2. Parents' education and nurses about telling story and non pharmacological management for nausea and vomiting.

Further research should be done on the effect of combination of listening to music and telling story as a management of chemotherapy induced nausea and vomiting.

\section{References}

1. Abd El Razik, S., (2010): Effect of Educational Program on Quality of life for Patients with cancer undergoing chemotherapy, doctoral Degree, Faculty of Nursing, Benha University.

2. Abdel Hadi, S., (2010): Comprehensive care in Pediatric Cancer patient, Pediatric oncology NCI, Egypt. Retrieved from wwww.nic.ed.eg.accssed.

3. Academy for Guided Imagery, (2010): certification training .Retrieved from: http//www. Academy for Guided Imagery.com 
4. American cancer society, (2015): Cancer facts and figures - 2006.A Gide for patient Atlanta; American cancer society Inc. Retrieved from: http//www.cancer.org/Pdf.

5. Burke T., Wisniewski T., \& Ernst F., (2016): Resource utilization and costs associated with chemotherapy-induced nausea and vomiting following highly or moderately emetogenic chemotherapy administered in the US outpatient hospital setting. Support Care Cancer, 19 (1): 131-40.

6. Elatter, (2008)Cancer Statistics, Department of Biostatstics\&Epidemiology .Retrieved from www.cancer.gov.eg

7. Hassan A., (2015): "Effect of Guided Imagery Relaxation Session and Story-Telling on the Intensity of Nausea and Vomiting among Children Undergoing Chemotherapy, doctoral Degree, Nursing, Tanta University.

8. Heinemann K., \& Boyce A., (2012): Emergencies in pediatric oncology. Therapeutic drugs. Chapter 13. Springer. New York, Pp. 105-106.

9. Kashaninia, (2016): Clinical characteristics associated with the development of anticipatory nausea and vomiting in patients with cancer undergoing chemotherapy treatment. Journal of Clinical Oncology, 94(8) 421- 446.

10. King, C., (2011): No pharmacologic management of chemotherapy - induced nausea and vomiting. Oncology nursing forum, 24(9):41-48.

11. Marler, A., (2008): Music or guided imagery for women undergoing colposcopy: A randomized controlled study of effects on anxiety, perceived pain and patient satisfaction. Journal of Lower Genital Tract Disease, 11(1):29- 45.

12. Martin, A., (2010): Measuring chemotherapy induced nausea and emesis. Cancer, 98(6):645655.

13. Mazlum S., Toghian N., Banihashem A., \& Behnam H., (2013): The effect of massage therapy on chemotherapy-induced nausea and vomiting in pediatric cancer, Iran Journal Nursing Midwifery Res, 18(4): 280-284.

14. Mohamed, W., (2006): Impact of nursing management protocol on selected side effects of chemotherapy in cancer patient. Unpublished Doctoral. Faculty of nursing, Cairo University.

15. National Cancer Institute (2017): Nausea and Vomiting PDQ- 19 (1): 131-40.

16. Rhodes, V., \& McDaniel, G., (1999): Nausea, Vomiting and retching the management of the symptoms experience. Seminar oncology nrse.11(10):256-5
17. Ries, S., (2011): Nausea Induced by Mental Images of Chemotherapy. Journal of Cancer, 24(6):629-36.

18. Roy, S., (2001): " Psychological Intervention with chemotherapy patients: Evaluation Outcome. Journal of Advances in Psychosomatic Medicine, 15 (6):23-50. 